\title{
Product quality improvement model considering quality investment in rework policies and supply chain profit sharing
}

\author{
Amanda Sofiana ${ }^{1} \cdot$ Cucuk Nur Rosyidi $^{2}$. Eko Pujiyanto ${ }^{2}$
}

Received: 18 October 2018 / Accepted: 1 March 2019 / Published online: 13 March 2019

(c) The Author(s) 2019

\begin{abstract}
The aim of this paper is to develop an optimization model for quality improvement by considering quality investment in rework policies and supply chain profit sharing. To improve product's quality, the decision of process target and its tolerance is important since it directly affects the defective rate, manufacturing cost, and loss to customer due to the deviation of product from its specification. In this research, two rework policies are considered. In the first policy, the rework is done by using the same manufacturing facility, while in the second policy a new process facility was added for rework. Quality improvement in the supply chain environment is also necessary. Hence, profit sharing system is added in the model to strengthen the commitment of the suppliers in improving component quality. In the system, the manufacturer shares the profits to the supplier if the supplier can meet or exceed the quality target specified by the manufacturer. A comparison is given to determine the best quality improvement policy between those two policies considering profit sharing system. From the results of the optimization, the managers can make economic investment decision economically to correct a defective product through cost optimization model and to choose the best option toward the goal of least unit production cost. By using this model, the decision-maker can evaluate any quality investment in order to achieve significant financial return.
\end{abstract}

Keywords Quality improvement · Quality investment $\cdot$ Quality incentive $\cdot$ Profit sharing $\cdot$ Variance reduction $\cdot$ Rework

\section{Introduction}

Recently, manufacturing sector is one of the very rapid growing sectors. In the process, a manufacturing company has to choose the right business strategy in order to compete with others. According to Porter (1980), business strategy is defined as the way companies take to compete in the market with the goal of getting the desired profit. According to Hallgren and Olhager (2006), there are several important

Amanda Sofiana

amanda.sofiana@gmail.com

Cucuk Nur Rosyidi

cucuk@uns.ac.id

Eko Pujiyanto

ekopujiyanto@ft.uns.ac.id

1 Department of Industrial Engineering, Faculty of Engineering, Universitas Jenderal Soedirman, Jl. Prof. Dr. HR. Boenyamin No. 708, Purwokerto 53122, Indonesia

2 Master Study Program of Industrial Engineering, Faculty of Engineering, Universitas Sebelas Maret, J1. Ir. Sutami No. 36A, Surakarta 57126, Indonesia aspects for manufacturing companies to compete in the dynamic global competition, namely quality improvement, cost reduction, and on-time delivery. Product quality and cost reduction have been considered as the most common competitive strategies used by many manufacturing companies. The manufacturing companies have to perform quality improvement in their products at minimum cost from time to time. There have been many researches on process quality improvement to minimize cost. One of the important variables in cost minimization is product tolerance value. According to Zhang (1996), tolerance is a critical issue in the design and manufacturing stage of a product, where the determination of tolerance will affect product and process design since the tolerance is the link between product design and manufacturing. This value is important since it serves to limit the variability of product quality around the target characteristics (Mustajib and Irianto 2010). In setting the tolerance, Taguchi (1989) introduced a quadratic loss function that reflects the balance between customers' loss due to the variation of product performances and producer's effort to improve the product quality. In Taguchi quality loss concept, quality improvement must be done by reducing the process 
variance as well as to get the mean value of the process as close as possible to its target.

Several studies have been conducted to combine manufacturing with quality loss cost in a tolerance design model. For example, researchers such as Taguchi et al. (1989), Kapur (1989), Fathi (1990), and Zhang and Hug (1992) have conducted some researches, but they have not considered both manufacturing cost and quality loss simultaneously. Vokurka and Davis (1996) provided a case study of manufacturing scrap reduction through quality improvement. Jeang (1997) developed a tolerance design approach for quality improvement and cost reduction. He minimized the total costs of tolerance and quality loss based on three cost estimation scenarios using response surface methodology. In further research, Jeang (2001) proposed a model for simultaneous optimization of product and process design parameters, which was expressed in a mathematical relationship to link the elements of design target, design tolerance, process mean, and process tolerance in one equation and combined the optimization of parameter and tolerance design over product/process in the early stage of design. For the consideration of reworked items, Chiu and Chiu (2003) presented an economic production quantity model, similar to the optimal lot sizing model, but for defective and scrap rates. Another research by Chiu (2003) considered the influence of the reworking of defective items by allowing backlogging. Chiu (2007) then developed an economic manufacturing quantity model for a case when there are some random defective items produced subject to rework or scrapping. The optimal levels of the lot-size and backlogs were set as the decision variables to minimize expected total cost consisting of setup cost, holding cost, repair cost, disposal cost, and shortage cost.

In the manufacturing process, it is commonly known that items vary in their performances due to some inevitable random variations, such as material, operator, method, or process. Quality inspection processes are generally conducted only at the final stage of the production process. With this only final-stage inspection process, it will make the defect product in the preceding process stage become undetected. The inspection at each stage of the production process is needed to reduce this problem. Inspection, which is usually accomplished using manual method, has been intensively replaced by the use of simple yet effective sensor technology. This technology has made in process or between-process inspection become feasible. In this way, the defect parts or components can be detected earlier to avoid bigger problems (Irianto 1996). In the process, defective products may need to be reworked so as to conform with the specifications. The model of overall inspection policy of each process was carried out previously by Lo and Tang (1990), especially for products with expensive components, in which each process should be carefully inspected before proceeding to the subsequent process. A research on inspection policy and rework was done by Irianto (1996). There were two policies proposed in the research: (i) using the same production process facility for rework/correction process, and (ii) using different rework/correction facility. The model considered the economic and investment aspects. In the first policy, no additional investment for quality improvement was considered. While in the second policy, the investment value of quality improvement was calculated from the investment of additional separate rework facilities. The model was then extended by Irianto and Rahmat (2008) by including the process selection in make-to-order company by considering inspection and rework at the same production line facility. Then, Irianto (2009) added consideration to the model with the imperfection on the inspection process. Jerusalem et al. (2016) proposes a new comprehensive model for process selection. It incorporates both offline and online quality controls, an excellent balance between the costs, tolerance as a quality requirement, and delivery time.

However, in Irianto's work, the model tends to select the second policy since it gives more benefit in the long term than the first policy. Thus, in this research we will enhance the first policy by adding quality investment to improve the quality of the process in terms of variance reduction. Quality investment models have been developed by Abdul-Kader et al. $(2008,2010)$. They conducted a research to model the possibility of reducing the cost of rework/scrap by adding quality investment. They adopted an investment which is expressed as the function of mean and variance. This quality investment model was also used by Chen and Tsou (2003), which was originally used as the basis of modeling the investment defined by Hong and Hayya (1993) and Ganeshan et al. (2001). Rosyidi et al. (2016a) developed a quality improvement model by variance reduction in component using learning investment. The model can be used to solve the problem of investment allocation to improve the quality of a product. Further, Rosyidi et al. (2016b) developed an investment allocation model for quality improvement to reduce component variances at manufacturer and supplier side to maximize the return on investment.

In addition to quality improvement in the form of rework policy selection and optimal investment value as mentioned previously, quality improvement in the supply chain environment is also necessary. Profit sharing system can be used in the supply chain to strengthen the commitment of the suppliers in improving component quality. In the system, the manufacturer shares the profits to the supplier if the supplier can meet or exceed the quality target specified by the manufacturer in the form of incentives. With this system, the suppliers will make their best effort to improve their product quality while minimizing costs throughout the supply chain. Profit sharing model in this research refers to the model of Kusukawa et al. (2006). In their research, profit sharing or 
rebates are given by the manufacturer or second-tier supplier to the first-tier suppliers who are capable of improving the quality so that the quality of the supplier process exceeds the quality target set by the manufacturer. Hence, the optimal quality targets must be achieved by the supplier to obtain optimal profit sharing. Research on the provision of incentives in improving process performance is also done by Overvest and Veldman (2008). They proposed a managerial incentives model to managers who can deliver the innovation or improvement in process performance using Cournot competition scheme. Furthermore, Veldman and Gaalman (2013) developed a model to determine the effect of incentive strategies for product quality and process improvement using game theory models in competition between two managers.

There are some other aspects that considered in several supply chain models regarding profit sharing. Panda et al. (2015) analyzed coordination of a manufacturer-distributer-retailer supply chain, where the manufacturer exhibited corporate social responsibility (CSR). In manufacturer-Stackelberg game setting, the paper proposed a contract bargaining process to resolve channel conflict and to distribute surplus profit among the channel members. Modak et al. (2015) proposed a two-echelon duopolistic retailers supply chain model with recycling facility considering Cournot and collusion behaviors of the retailers. The paper explored channel coordination and profit distribution in a two-layer socially responsible supply chain that consisted of a manufacturer and two competitive retailers. Further, Modak et al. (2018a) developed a model with three different structures of two-echelon closed-loop supply chain (CLSC) under price and product quality-dependent deterministic demand environment where product price, quality level, and recycling rate were considered as the decision variables. They also developed in other research a model that dealt with a manufacturer-retailer supply chain considering the cost of greenhouse gas (GHG) emission during manufacturing process (Modak et al. 2018b). Revenue sharing contract and asymmetric Nash bargaining strategy were used in that research to resolve channel conflict and to share surplus profit between the channel members.

In this paper, we develop a mathematical model that can be used to determine the optimal tolerance, rework policy, and profit sharing that should be given by the manufacturer or second-tier supplier to the first-tier suppliers. The main contribution of this research lies in the integration of profit sharing, learning, and facility investment in a quality investment decision model which will make the suppliers commit to the efforts of quality improvements and the manufacturer gains maximum benefits from those sharing and investments. A numerical example is given in this paper to show the application of the proposed model. This research will be beneficial to a decision-maker in companies engaged with manufacturing in the global competition and respond to managerial issues related to production and business decisions.

\section{Problem definition}

A manufacturing company needs to improve their product quality by reducing the component variance of their manufactured products. To reduce the variance, an inspection and rework process of defective items need to be done. In this case, the manufacturer has two options: (1) using the same facility to rework the defective items, or (2) adding separate rework facility. In this paper, we assume the reworked product still has the probability to be defect, so it can be reworked multiple times until it meets the required specification. The first policy is chosen due to its simplicity, that is, reworking the defect units by using the existing facility. In this first policy, quality investment is made by considering learning investment to reduce the variance. This investment can be used for training, technological improvements, as well as other efforts related to the variance reduction. The second policy has two advantages. It may have higher capacity due to uninterrupted process in main facility of production process and the rework can be done better than the process in the main production line. However, the second policy needs a big additional investment to purchase and setup of new facility.

In addition to quality improvement in the manufacturer side above, quality improvement in the suppliers' side also needs to be done. To meet market demand, the company also outsources the needed components to its suppliers. Profit sharing system is implemented for the suppliers to improve the quality of their products. With such system, suppliers will strive to improve their production quality while minimizing the cost of quality which will make the whole supply chain become more efficient. Suppliers in this system consist of several tiers. Figure 1 illustrates the supplier network in this system. Outsourcing activities within the model are manufacturing process outsourcing activities, where the raw materials of component are assumed to be supplied by the manufacturer. The first-tier suppliers provide some manufacturing processes to transform raw materials into semifinished components. Then, the supplier on the second tier continues the manufacturing process from the semifinished component to the finished component. The finished components are then shipped to the manufacturer. Each supplier has a different quality level. It will affect the cost of failure and appraisal cost of each supplier. Second-tier suppliers and manufacturers bear the cost of failure caused by the level of process quality at the first-tier suppliers. Each supplier, before delivering the component to the next-tier supplier, will perform component quality inspection so that appraisal cost will be incurred on each supplier. The manufacturer 


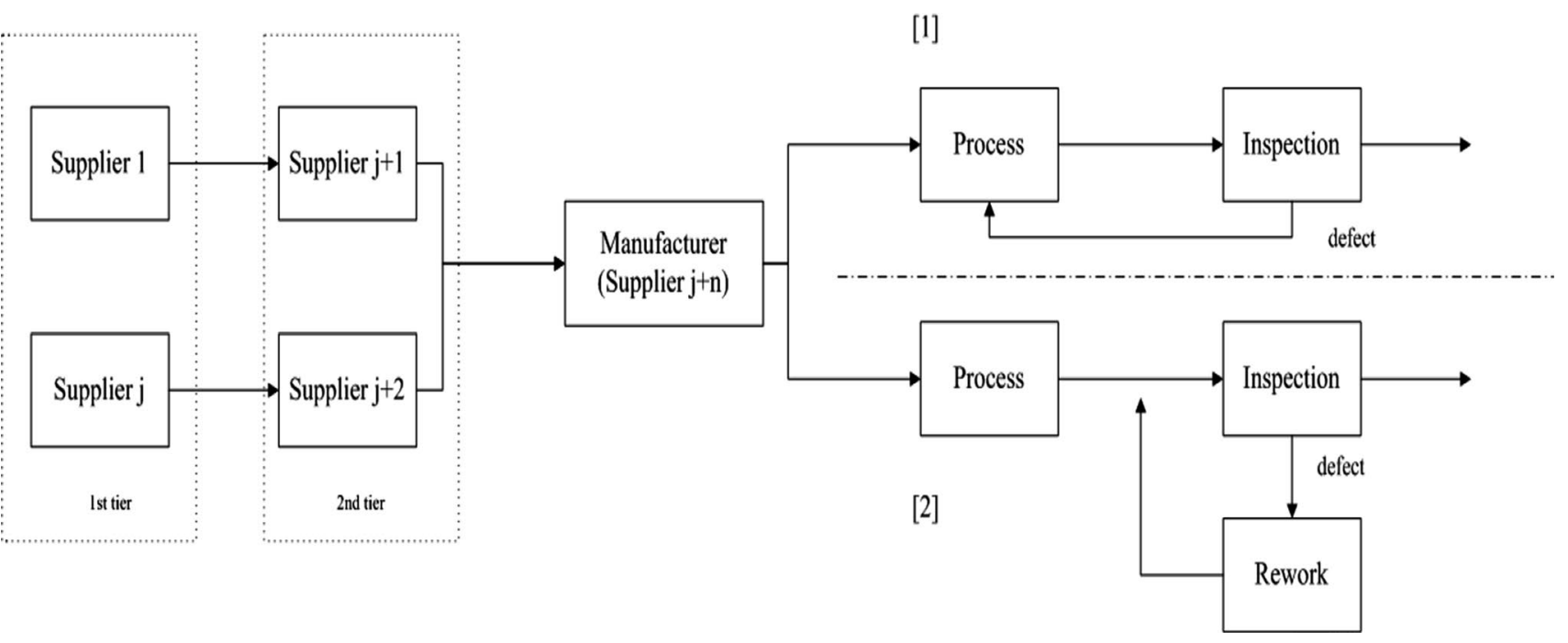

Fig. 1 Rework and supply chain system

conducts inspection once the component arrives, so it will also need appraisal cost. The quality level of each supplier will affect the amount of profit sharing. If the quality level of the supplier process exceeds the quality target set by the manufacturer, then the supplier at the previous tier will receive a rebate in the form of profit sharing. The decision variable is quality level of component to minimize the total cost of quality.

Our concern in this paper is the quality improvement in a product to minimize costs related to the improvement effort and the quality investment related to both policies. Tradeoff between two conflicting objectives, which is cost and quality, is unavoidable. This happens because the company has to spend more on quality costs and manufacturing costs to make a better quality product. The quality loss in terms of the inspection and rework cost is integrated and then minimized to obtain the optimal tolerance value for each policy based on their most economical performance. This optimization procedure not only leads us to set the most economical tolerance and profit sharing, but also simultaneously helps the management in selecting or evaluating the policies concerning inspection and rework to improve the product quality.

\section{Model formulation}

\section{External quality loss cost formulation}

In this research, $y$ denotes quality characteristic of a product with a mean value of $\mu$ which is assumed to be equal to the target value $m$. Tolerance value is denoted by $t$ in which a product may be considered as defective if it does not meet the tolerance specification. Hence, there will be a quality cost known as customer loss denoted by $L(y)$ in which according to Taguchi et al. (1989), the customer will be perfectly satisfied if the quality characteristics are at the target value, otherwise there will be customer dissatisfaction expressed in quadratic function as follows:

$L(y)=k(y-m)^{2}$.

In Eq. (1), $k$ is a cost coefficient whose value is derived from $K=C_{0} / \Delta_{0}^{2}$. The value of $C_{0}$ is determined by summing up all the components of the cost incurred due to the loss of quality such as the cost of lost time, the cost of replacement (repair), transportation, and other related costs. By using the above loss function, the expected cost of quality loss of each product can be estimated by Eq. (2)

$E[L(y)]=\int_{m-t}^{m+t} k(y-m)^{2} \cdot f(y) \mathrm{d} y$.

In Eq. (2), $f(y)$ is the probability density function of $y$. If $y$ is normal distribution $N\left(m, \sigma^{2}\right)$, then the probability density function of $y, f(y)$, is:

$f(y)=\frac{e^{-\frac{(y-\mu)^{2}}{2 \sigma^{2}}}}{\sqrt{2 \pi} \sigma}$.

\section{Manufacturing cost formulation}

The next cost component comes from the production line. It is assumed that all defective products can be reworked with the same facilities that already exist or with the addition of rework facility. Since the rework is only done for the 
defective product, the total cost of the correction depends on the tolerance value $t$. Inspection costs also need to be considered. This cost comes from all the products that are inspected, both defective and good ones. Therefore, the tolerance value also affects the cost of inspection because the defective product also needs to be re-inspected.

$M C$ is total cost per unit consisting of the cost of manufacturing process, rework, and inspection. The estimated total cost per unit product is expressed as follows:

$M C_{m}=\frac{\left(n_{i_{m}} \cdot c_{i_{m}}\right)+\left(n_{p_{m}} \cdot c_{p_{m}}\right)+\left(n_{c_{m}} \cdot c_{c_{m}}\right)}{n_{p_{m}}}$,

where $n_{i}=$ the number of inspected components in one production cycle, $n_{p}=$ the number of components produced in one production cycle, $n_{c}=$ the number of reworked components in one production cycle, $c_{i}=$ inspection cost/unit, $c_{p}=$ production process cost/unit, $c_{c}=$ rework cost/unit, $m=$ policy reworks choices $(1,2)$.

\section{Number of good, corrected, and inspected products}

Let the output of production is assumed to be normally distributed from both production facility $f(y)$ and the correction facility $g(y)$ and denoted by $N\left(\mu, \sigma_{1}^{2}\right)$ and $N\left(\mu, \sigma_{2}^{2}\right)$. We assume that the correction facility gives better output than correction facility, and then $\sigma_{1}>\sigma_{2}$. Hence, the probability of good product coming from the process $P_{1}$ is less than that of the product comes from the correction facility $P_{2}$. The estimated operating time for production is $T$. So the total time required for the process and correction must be less than or equal to $T$. The number of products, corrected products, and inspected products in policy $j$ are denoted by $n_{p j}, n_{c j}$, and $n_{l j}$, respectively. The probability of this good product can be formulated as follows:

$P_{1}=\int_{\mu-t}^{\mu+t} f(y) \mathrm{d} y$.

$P_{2}=\int_{\mu-t}^{\mu+t} g(y) \mathrm{d} y$.

Given the production operating time estimates for production by $T$, the total time required for the process and rework must be less than or equal to $T$. Hence, what needs to be estimated is the number of product outputs. The operating time of Policy 1 is the total time used by process and correction activities as expressed in Eq. (7).

$n_{p_{1}} \cdot t_{p}+n_{c_{1}} \cdot t_{c} \leq T$.
The number of inspected products is obtained using the following formula:

$n_{I_{1}}=n_{p_{1}}+n_{c_{1}}$.

Then, the average number of corrected products is estimated using the following formula:

$n_{c_{1}}=n_{p_{1}} \cdot \overline{P_{1}}$,

where $1=1-P_{1}$. Since the corrected product still has the possibility of defects, the probability in Eq. (9) will become $\overline{P_{1}} /\left(1-\overline{P_{1}}\right)$, thus:

$n_{c_{1}}=n_{p_{1}} \cdot \overline{P_{1}} /\left(1-\overline{P_{1}}\right)$.

By substituting Eq. (10) into Eq. (7), we can get the following:

$n_{p_{1}} \cdot t_{p}+n_{p_{1}} \cdot \frac{\overline{P_{1}}}{1-\overline{P_{1}}} \cdot t_{c} \leq T$.

Then, the number of products is calculated as in Eq. (12) which will eventually affect $n_{c l}, n_{I I}$.

$n_{p_{1}} \leq \frac{T}{\left(t_{p}+t_{c} \cdot \overline{P_{1}} /\left(1-\overline{P_{1}}\right)\right)}$.

For Policy 2, the total operating time is dominated solely by product process activities, thus:

$n_{p_{2}} \cdot t_{p} \leq T$.

However, if the number of corrected products is large, then $n_{c_{2}} \cdot t_{c} \leq T$ should also be considered. The corrected product has the possibility of defects after correction so that:

$n_{c_{2}}=n_{p_{2}} \cdot \overline{P_{1}} /\left(1-\overline{P_{2}}\right)$.

Since the values of $n_{p 2}$ and $n_{c 2}$ are constrained by $T$, the following two conditions will hold:

1. If $t p \leq t c \cdot \overline{P_{1}} /\left(1-\overline{P_{2}}\right)$, then $n_{p_{2}} \leq t / t p$

2. Otherwise $n_{p_{2}} \leq T /\left(t_{c} \cdot \overline{P_{1}} /\left(1-\overline{P_{2}}\right)\right)$.

The number of inspected products is also constrained by $T$, and the following condition will hold:

$n_{p_{2}} \geq n_{p_{1}}$

From Eq. (15), we can observe that without quality investment, the output of the second policy is higher than the first. 


\section{Internal failure cost, prevention and appraisal cost, and rebate}

In this paper, the following cost components are adopted from Kusukawa et al. (2006): internal quality failure cost, prevention and appraisal cost, and rebate. Equation (16) shows the objective function:

$C_{r j}\left(q_{j}\right)=C_{l j}\left(q_{j}\right)+C_{p j}\left(q_{j}\right)-R_{j}\left(q_{j}\right)$,

where $C_{r j}\left(q_{j}\right)=$ cost of quality at supplier $j$ when quality level is $q_{j}$ and receive rebate for $R_{j}\left(q_{j}\right), C_{l j}\left(q_{j}\right)=$ internal quality failure cost to supplier $j$ when quality level is $q_{j}$, $C_{p j}\left(q_{j}\right)=$ prevention and appraisal cost to supplier $j$ when quality level is $q_{j}, R_{j}\left(q_{j}\right)=$ rebate received by supplier $j$ when quality level is $q_{j}$.

The failure cost calculation at supplier $j$ is given in Eq. (17) where supplier $j$ incurs not only failure cost resulted from the quality level at process of supplier $j$, but also the failure cost caused by quality level at the process of predecessor supplier $i$.

$C_{l j}\left(q_{j}\right)=\sum_{i \varepsilon S}\left(1-q_{j}\right) l_{i j}$,

where $q_{j}=$ optimum quality level of process at supplier $j$, and $L_{i j}=$ quality failure cost by supplier $j$ resulting from defective product from supplier $i$.

Total prevention and appraisal cost is given in Eq. (18). When the predecessor suppliers perform quality improvement, the appraisal cost of subsequent suppliers will decrease, due to the decrease in component inspection cost.

$C_{p j}\left(q_{j}\right)=m_{j}^{\frac{q_{j}}{r_{j}}}+b_{j}$

$r_{j}=\prod_{i \in S} w_{i j}$,

where $m_{j}$ and $b_{j}$ are cost parameters used to calculate prevention and appraisal costs of supplier $j$, while $r_{j}$ is calculated based on $w_{i j}$, which is given as:

$w_{i j}=\left\{\begin{array}{ll}q_{i}, & \text { if supplier } i \\ 1, & \text { is predecessor of supplier } j \\ \text { otherwise }\end{array}\right.$.

Equation (21) shows the quality cost of all suppliers on a system that has not yet implemented a rebate:

$C^{S *}=\sum_{j \in S} C_{j}\left(q_{j} *\right)=\sum_{j \in S} C_{l j}\left(q_{j} *\right)+C_{p j}\left(q_{j} *\right)$.

The optimal quality level of process at supplier $j$ before rebate is shown in Eq. (22). The optimal quality target value $q_{j}^{*}$ in the case without rebate can be obtained as a solution of partial differential with respect to qj in Eq. (21) as: $q_{j}^{*}=r_{j} \frac{\gamma_{j}-\ln \delta_{j}+\ln r_{j}^{*}}{\delta_{j}}$,

where

$\gamma_{j}=\ln l_{j j}$

$\delta_{j}=\ln m_{j}$

$r_{i}^{*}=\prod_{i \in S} w_{i j}^{*}$

$w_{i j}=\left\{\begin{array}{ll}q_{i}, & \text { if supplier } i \text { is predecessor of supplier } j \\ 1, & \text { otherwise }\end{array}\right.$.

Equation (27) shows the total cost of all suppliers in the rebate system.

$C^{S * *}=\sum_{j \in S} C_{j}\left(q_{j}^{* *}\right)=\sum_{j \in S} C_{l j}\left(q_{j}^{* *}\right)+C_{p j}\left(q_{j}^{* *}\right)-R_{j}\left(q_{j}^{* *}\right)$.

The optimal quality target value of supplier $j$ in the case with rebate, $q_{j}^{* *}$, can be obtained as a solution of partial differential with respect to $q_{j}$ in Eq. (27) as:

$q_{j}^{* *}=r_{j} \frac{\varepsilon_{j}-\ln \delta_{j}+\ln r_{j}^{* *}}{\delta_{j}}$,

where

$\varepsilon_{j}=\ln r_{j} \sum_{j \in S} l_{i j}$

$r_{j}^{* *}=\prod_{i \in S} w_{i j}^{* *}$

$w_{i j}=\left\{\begin{array}{ll}q_{i}, & \text { if supplier } i \text { is predecessor of supplier } j \\ 1, & \text { otherwise }\end{array}\right.$.

The concept of rebate assumes that the optimal quality target with rebate is higher than the quality level without rebate. The quality target and rebate values for each supplier are set by the manufacturer. If the quality level of supplier $j$ exceeds a predetermined quality target, supplier $j$ will receive a rebate from the manufacturer or supplier of the next related tier.

Rebate consists of fix remuneration $U_{j}$ and variable remuneration $\kappa_{j}$ paid every time the quality level exceeds the quality target. The amount of rebate which is received by the supplier can be expressed in Eq. (32).

$R_{j}\left(q_{j}\right)=\left\{\begin{array}{cc}\kappa_{j}\left(q_{j}-T_{j}\right)+U_{j}, & \left(q_{j} \geq T_{j}\right) \\ 0, & \left(q_{j}<T_{j}\right)\end{array}\right.$ 
where $\kappa_{j}=$ variable remuneration, $q_{j}=$ process quality level at supplier $j, T_{j}=$ quality level target value for supplier $j$, and $U_{j}=$ fix remuneration.

There are three rules used to determine the value of optimal $\kappa_{j}, T_{j}$, and $U_{j}$ :

1. When supplier $j$ achieved the optimal quality target value $q_{j}{ }^{* *}$ after setting rebate, quality cost of supplier $j$ can be minimized.

2. When quality cost of supplier $j$ after setting rebate is minimized, cost reduction ratio between quality cost of supplier $j$ with rebate and that without rebate is equivalent to cost reduction ratio of total quality cost obtained from the whole supply chain system with rebate.

3. Target of supplier $j, T j$, is set as a higher value than the optimal quality target value of supplier $j$ without rebate, $q_{j}^{*}$.

Variable remuneration will be received by suppliers if they exceed the quality target where the value of variable remuneration is linear with the quality improvement in suppliers. The optimum variable remuneration is expressed in Eq. (33). This equation is obtained from minimizing Eq. (27).

$\kappa_{j}=\max \left(\frac{m_{j}^{q_{j}^{* * *}} \ln m_{j}}{r_{j}^{* * *}}-x_{i j}\left(1-q_{i}^{* *}\right) l_{j j}, 0\right)$.

In accordance with the second rule, cost reduction ratio of total quality cost in the whole supply chain system with rebate and the minimum value of total quality cost in the whole system without rebate is expressed in Eq. (34).

$\rho=\left(C^{S *}-C^{S * *}\right) / C^{S *}$.

Cost reduction ratio of quality cost of supplier $j$ in Eq. (34) is equivalent to the cost reduction ratio of total quality cost in the whole system. The rebate $R j\left(q j^{* *}\right)$ paid for relevant supplier $j$ who achieved improvement in quality level can be calculated as:

$R_{j}\left(q_{j}^{* *}\right)=C_{j}\left(q_{j}^{* *}\right)-(1-\rho) C_{j}\left(q_{j}^{*}\right)$.

Quality-level target $T_{j}$ is obtained by substituting Eq. (35) to Eq. (32), to result Eq. (36).

$T_{j}=q_{j}^{* *}-\frac{C_{j}\left(q_{j}^{* *}\right)-(1-\rho) C_{j}\left(q_{j}^{*}\right)-U_{j}}{\kappa_{j}}$.

To fulfill the third rule, which is to avoid $T_{j}$ lower than $q_{j}^{*}$, $T_{j}$ is set as follows:
$T_{j}=\max \left(q_{j}^{* *}-\frac{C_{j}\left(q_{j}^{* *}\right)-(1-\rho) C_{j}\left(q_{j}^{*}\right)-U_{j}}{\kappa_{j}}, q_{j}^{*}\right)$.

Taking into account the critical point when the quality target value $T_{j}$ equals the value of $q_{j}^{*}$, the optimal value of $U_{j}$ can be obtained from the following equation:

$q_{j}^{* *}-\frac{C_{j}\left(q_{j}^{* *}\right)-(1-\rho) C_{j}\left(q_{j}^{*}\right)-U_{j}}{\kappa_{j}}=q_{j}^{*}$.

Then, the optimal value of $U_{j}$ can be simplified as shown in Eq. (39)

$U_{j}=\max \left(C_{j}\left(q_{j}^{* *}\right)-(1-\rho) C_{j}\left(q_{j}^{*}\right)-\kappa_{j}\left(q_{j}^{* *}-q_{j}^{*}\right), 0\right)$.

\section{Total cost formulation}

The total cost formulation consists of external quality loss costs, manufacturing costs, internal failure costs, prevention and appraisal costs, and rebates. The formulation is shown in Eq. (40).

$$
\begin{aligned}
T C_{m}= & E[L(y)]+M C_{m}+C_{l j}\left(q_{j}^{* *}\right) \\
& +C_{p j}\left(q_{j}^{* *}\right)-\left(\kappa_{j}\left(q_{j}^{* *}-T_{j}\right)+U_{j}\right) .
\end{aligned}
$$

Since the quality level in Eq. (40) is in the form of percentage, to express it in the form of tolerance and variance, the value $q_{j}$ is obtained by the following equation.

$q_{j}^{* *}=\int_{\mu-t}^{\mu+t} \frac{e^{-\frac{(y-\mu)^{2}}{2 \sigma^{2}}}}{\sqrt{2 \pi} \sigma} \mathrm{d} y$

From the result of Eq. (41), the value of $q_{j}^{* *}$ can be obtained:

$q_{j}^{* *}=\operatorname{Erf}\left[\frac{t^{*}}{\sqrt{2} \sigma}\right]$.

The value of optimal tolerance $t^{*}$ can be obtained by minimizing Eq. (40) with respect to $t$.

\section{Quality improvement model with learning investment for Policy 1}

After determining the optimal tolerance, we add a learning investment model to determine the amount of quality investment required for quality improvement to minimize the 
production cost. Hence, the model will provide simultaneous joint decisions to achieve optimal process setting, which are optimal investment and optimal variance and mean values after the investment. By adding the investments, there will be a reduction in cost.

According to Hong and Hayya (1993), Ganeshan et al. (2001), Chen and Tsou (2003), and Abdul-Kader et al. (2010), the process parameter values of $\mu_{I}$ and $\sigma_{I}$ can be expressed as in Eq. (43) and (44).

$\sigma_{I}^{2}=\sigma_{L}^{2}+\left(\sigma_{M}^{2}-\sigma_{L}^{2}\right) e^{(-\alpha I)}, \quad \alpha>0$

$\mu_{I}^{2}=\mu_{L}^{2}+\left(\mu_{0}^{2}-\mu_{T}^{2}\right) e^{(-\beta I)}, \quad \beta>0$,

where $\sigma_{M}^{2}$ denotes the variance before quality improvement and $\sigma_{L}^{2}$ denotes the best variance that can be achieved by the system, while $\mu_{0}$ denotes the initial value of mean and $\mu_{T}$ denotes its target value.

According to Abdul-Kader et al. (2010), when the quality characteristic $Y$ follows normal distribution, the density function $f\left(Y, I_{1}\right)$ of quality characteristics $Y$ with the investment of $I_{1}$ is expressed as the following equation:

$f\left(Y, I_{1}\right)=\frac{1}{\sigma_{I} \sqrt{2 \pi}} e^{\frac{\left(Y-\mu_{I}\right)^{2}}{2 \sigma_{I}^{2}}}$.

Taguchi $L(Y)$ loss function is used in this paper, so the quality loss per unit product can be derived as in Eq. (46):

$L\left(Y, I_{1}\right)=\int_{m-t}^{m+t} L(Y) x f\left(Y, I_{1}\right) \mathrm{d} Y$.

Optimal quality investment can be found by minimizing total cost per unit. The total cost for Policy 1 can be obtained by substituting the external quality loss in Eq. (40) with Eq. (46). Then, the initial variance and mean process values are substituted into Eqs. (43) and (44) and summed with the investment value of $I_{1}$ to result the following equation:

$$
\begin{aligned}
T C\left(Y, I_{1}\right)= & L\left(Y, I_{1}\right)+M C_{1}+C_{l j}\left(q_{j}^{* *}\right)+C_{p j}\left(q_{j}^{* *}\right) \\
& -\left(\kappa_{j}\left(q_{j}-T_{j}\right)+U_{j}\right)+\frac{I_{1}}{n_{p_{1}}} .
\end{aligned}
$$

The optimal investment value $I_{1}$ and the optimum variance can be obtained by minimizing Eq. (47) and by substituting the optimum tolerance value previously obtained.

\section{Quality improvement model with investment for Policy $\mathbf{2}$ and rework policy selection}

In Policy 2, the company will make an investment to build a separate rework facility. The addition of rework facility is invested economically with a value of $I_{2}$ per determined investment period. To compare the quality investment between two policies, the investment will be calculated considering the number of final products that can be reworked by the two policies. Thus, Policy 2 is better than Policy 1 if:

$T C_{1}+\frac{I_{1}}{n_{p_{1}}}>T C_{2}+\frac{I_{2}}{n_{p_{2}}}$

\section{Numerical example}

Consider a component that should be processed and inspected one by one (unit production). Assume that the inspection facility is perfect. Suppose the output characteristic of a process $y$ follows a normal distribution function $N(\mu$, $\sigma_{1}^{2}$ ). Under the second policy, the correction facility gives a better output that follows a normal distribution function $N(\mu$, $\sigma_{2}^{2}$ ), where $\sigma_{1}>\sigma_{2}$. The input parameters for the numerical example are as follows:

\begin{tabular}{ll}
\hline Target process mean $m$ & $402 \mathrm{~mm}$ \\
Current process mean $\mu$ & $402.86 \mathrm{~mm}$ \\
Current standard deviation $\sigma_{1}$ & 0.66 \\
Standard deviation of rework facility $\sigma_{2}$ & 0.53 \\
The best variance that can be achieved & 0.55 \\
$\quad$ after quality improvement $\sigma_{L}$ & \\
Total manufacturing time $T$ & 10,000 unit time duration \\
Processing time/unit $t_{p}$ & 10 time duration \\
Rework time/unit $t_{c}$ & 10 time duration \\
Inspection time/unit $t_{i}$ & 1 time duration \\
Processing cost/unit $c_{p}$ & $\$ 2$ \\
Rework cost/unit $c_{c}$ & $\$ 2$ \\
Inspection cost/unit $c_{i}$ & $\$ 0.3$ \\
Taguchi loss constant $K$ & $\$ 1$ \\
Variance curve constant $\alpha$ & 0.00362 \\
Mean curve constant $\beta$ & 0.0105 \\
Cost of investment adding rework facility & $\$ 225$
\end{tabular}

Fixed cost and variable cost for operating the correction facility and rework per unit product are assumed to be $\$ 40$ and $\$ 2$, respectively.

In this paper, it is assumed that there are two-tier suppliers in which each tier consists of two suppliers. The suppliers in the first tier produce semifinished components and deliver them to the suppliers in the second tier. The secondtier suppliers produce final components and deliver them to the manufacturer. Figure 2 shows the description of the two-tier supply chain used in the numerical example. Table 1 and Table 2 show the parameters of internal quality failure costs and prevention and appraisal costs.

The model is solved using Wolfram Mathematica 7.0 software. From the optimization results, optimum tolerance value of the manufacturer, the optimal investment value of 


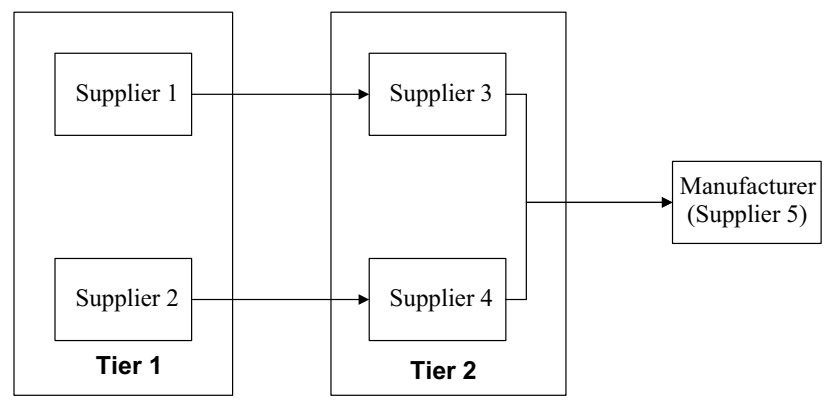

Fig. 2 Two-tier supplier chain in numerical example

Table 1 Quality failure cost of each supplier

\begin{tabular}{llllll}
\hline & \multicolumn{5}{l}{ Failure cost (\$) } \\
\cline { 2 - 5 }$j / i$ & 1 & 2 & 3 & 4 & 5 \\
\hline 1 & 3 & 0 & 0 & 0 & 0 \\
2 & 0 & 2 & 0 & 0 & 0 \\
3 & 2 & 0 & 4 & 0 & 0 \\
4 & 0 & 2 & 0 & 3 & 0 \\
5 & 0 & 0 & 3 & 3 & 5 \\
\hline
\end{tabular}

Table 2 Prevention and appraisal cost of each supplier

\begin{tabular}{llllll}
\hline \multicolumn{6}{c}{} \\
\cline { 2 - 6 } & 1 & 2 & 3 & 4 & $\begin{array}{l}\text { Appraisal and prevention cost }(\$) \\
\text { (manu- } \\
\text { facturer) }\end{array}$ \\
\hline$m_{j}$ & 2.7 & 2.2 & 2.8 & 2.3 & 2.6 \\
$b_{j}$ & 1 & 1.5 & 1.3 & 2 & 1.2 \\
\hline
\end{tabular}

the rework Policy 1, optimal rebates, and the optimal quality level of each supplier are obtained simultaneously. Table 3 shows the optimization results at the manufacturer side.

From Table 3, we can see that rework Policy 1 is economically more preferable than the rework Policy 2 . From the optimization result, Policy 1 gives $\$ 0.111$ investment value/ unit product with $\$ 7.58$ production cost/unit, while the second policy provides an investment value/unit of $\$ 0.226$ with a $\$ 7.83$ production cost/unit. But in terms of quality, rework Policy 2 provides better quality with the tolerance value of $1.255 \mathrm{~mm}$ than Policy 1 at $1.432 \mathrm{~mm}$. In rework Policy 1, the number of components produced is 970 units. However, after the quality investments that affect the decrease in process variance, the number of components that can be produced increased to 978 units. The decrease in this variance affects the probability of defective components which will become smaller, so that the good components produced will be increased. Figure 3 shows the optimal solution graph of the tolerance value for both rework policies.

Figure 4 shows the graph of how the optimal quality investment of Policy 1 is obtained. The optimal quality investment is found to be $\$ 108.615$ with minimum total cost per unit of $\$ 7.58$.

Table 4 shows the results of the total quality cost on each supplier prior to the application of the rebate. The result is obtained from the application of Eq. (17) to Eq. (26) to find the optimal quality level and total quality cost on each supplier before rebate. The value is the same for each rework policy in manufacturer level.

Table 5 shows the results of the total quality cost on each supplier with rebate. The value of $q_{i}{ }^{* *}$ in manufacturer side is resulted by substituting the value of $t^{*}$ obtained from the total cost minimization in Eq. (40) which is converted into quality level form as in Eq. (42). The value is different for each rework policy at the manufacturer level due to the consideration of rework policy. Table 5 shows the quality level of product at the manufacturer side in which rework Policy 1 is higher than Policy 2.

Table 6 shows the calculation results of the rebate components in terms of fixed remuneration rebate $U_{j}$ and variable remuneration $\kappa_{j}$ paid every time the quality level exceeds the target quality. This value is obtained from Eq. (33) to Eq. (39). Zero values in the table show that the manufacturer gives profit sharing to its suppliers.

Table 7 shows the amount of depreciation of the quality cost after the application of the rebate. Suppliers 1 to 4 show a $20 \%$ reduction in quality costs. While the manufacturer shows a reduction of $22 \%$ for rework Policy 1 and $23 \%$ for rework Policy 2. Rework Policy 2 gives more benefit for
Table 3 Optimization results at the manufacturer side

\begin{tabular}{ll}
\hline Rework Policy 1 & Rework Policy 2 \\
\hline $\begin{array}{l}\text { Optimal tolerance }=1.432 \mathrm{~mm} \\
\text { Total cost/unit }=\$ 7.58\end{array}$ & $\begin{array}{l}\text { Optimal tolerance }=1.255 \mathrm{~mm} \\
\text { Total cost } / \text { unit }=\$ 7.83 \\
\text { Investment quality }=\$ 108.615\end{array}$ \\
$\begin{array}{l}\text { Amount produced before investment }=970 \text { units } \\
\text { Amount produced after investment }=978 \text { units }\end{array}$ & \\
Investment quality $/$ unit $=\$ 0.111$ & Amount produced $=996$ units \\
Optimal mean after investment $=402.27 \mathrm{~mm}$ & Investment quality $/$ unit $=\$ 0.226$ \\
Optimal variance after investment $=0.626$ & $\begin{array}{l}\text { Process mean after investment }=402.86 \mathrm{~mm} \\
\text { Process variance after investment }=0.53\end{array}$ \\
\hline
\end{tabular}




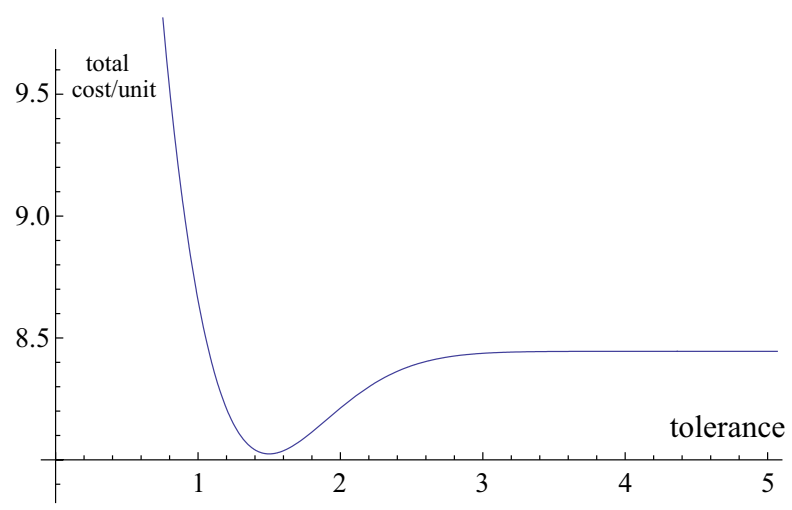

(a)

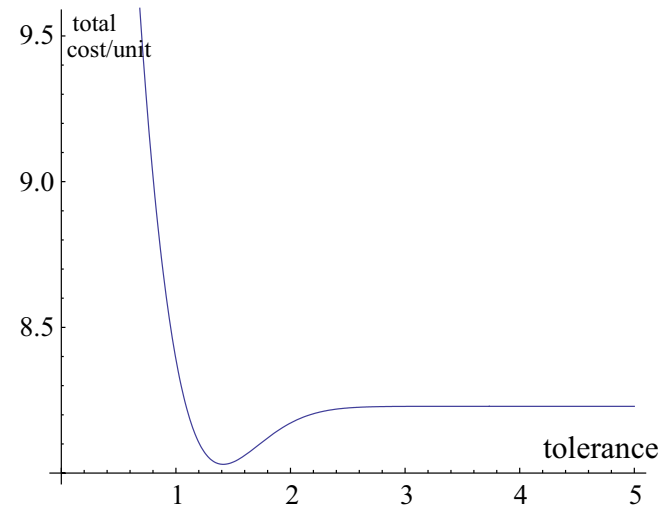

(b)

Fig. 3 Optimal tolerance value with total cost per unit plot of a Policy 1 and $\mathbf{b}$ Policy 2

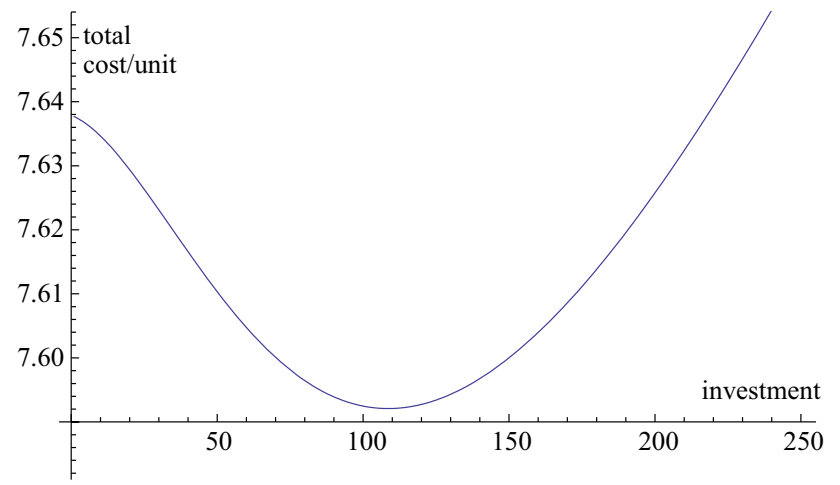

Fig. 4 Optimal quality investment value with total cost per unit plot of Policy 1

Table 4 Total cost of quality of each supplier before rebate

\begin{tabular}{lllll}
\hline Sj & $q^{*}$ & Failure cost (\$) & $\begin{array}{l}\text { Prevention and } \\
\text { appraisal }(\$)\end{array}$ & $\begin{array}{l}\text { Total before } \\
\text { rebate }(\$)\end{array}$ \\
\hline S1 & 0.894 & 0.32 & 3.70 & 4.02 \\
S2 & 0.867 & 0.27 & 3.70 & 3.97 \\
S3 & 0.911 & 0.57 & 4.46 & 5.03 \\
S4 & 0.836 & 0.76 & 4.61 & 5.37 \\
S5 & 0.879 & 1.36 & 4.70 & 6.07 \\
\hline
\end{tabular}

the manufacturer since it gives higher cost reduction than rework Policy 1.

To gain further insights into the behavior of the model and also the managerial implications, we perform a sensitivity analysis. The important parameter that affects both decision variable and objective function is $K$. Figure 5 depicts the optimal tolerance for different $K$ values. It is evident that as $K$ increases, the optimal tolerance will decrease or get tighter. If the $K$ value increases, it means the quality of the
Table 5 Total cost of quality of each supplier after rebate

\begin{tabular}{llllll}
\hline Sj & $q i^{* *}$ & $\begin{array}{l}\text { Failure cost } \\
(\$)\end{array}$ & $\begin{array}{l}\text { Prevention } \\
\text { and appraisal } \\
(\$)\end{array}$ & Rebate $(\$)$ & $\begin{array}{l}\text { Total after } \\
\text { rebate }(\$)\end{array}$ \\
\hline S1 & 0.945 & 0.16 & 3.70 & 0.65 & 3.21 \\
S2 & 0.931 & 0.14 & 3.70 & 0.67 & 3.17 \\
S3 & 0.925 & 0.41 & 4.27 & 0.65 & 4.03 \\
S4 & 0.885 & 0.48 & 4.45 & 0.63 & 4.30 \\
S5 (1) & 0.978 & 0.68 & 4.41 & 0.37 & 4.72 \\
S5 (2) & 0.982 & 0.66 & 4.41 & 0.38 & 4.69 \\
\hline
\end{tabular}

Table 6 Rebate component of each supplier

\begin{tabular}{llll}
\hline Sj & $T j$ & $\kappa_{j}(\$)$ & $U j(\$)$ \\
\hline S1 & 0.894 & 2.67 & 0.51 \\
S2 & 0.867 & 1.73 & 0.55 \\
S3 & 0.911 & 3.20 & 0.61 \\
S4 & 0.836 & 2.13 & 0.53 \\
S5 (1) & 0.879 & 3.72 & 0.00 \\
S5 (2) & 0.879 & 3.73 & 0.00
\end{tabular}

Table 7 Quality cost reduction ratio of each supplier

\begin{tabular}{llll}
\hline Sj & $\begin{array}{l}\text { Total before } \\
\text { rebate }(\$)\end{array}$ & $\begin{array}{l}\text { Total after } \\
\text { rebate }(\$)\end{array}$ & $\begin{array}{l}\text { Reduction ratio } \\
\text { of quality cost } \\
(\%)\end{array}$ \\
\hline S1 & 4.02 & 3.21 & 20 \\
S2 & 3.97 & 3.17 & 20 \\
S3 & 5.03 & 4.03 & 20 \\
S4 & 5.37 & 4.30 & 20 \\
S5 (1) & 6.07 & 4.72 & 22 \\
S5 (2) & 6.07 & 4.69 & 23 \\
\hline
\end{tabular}




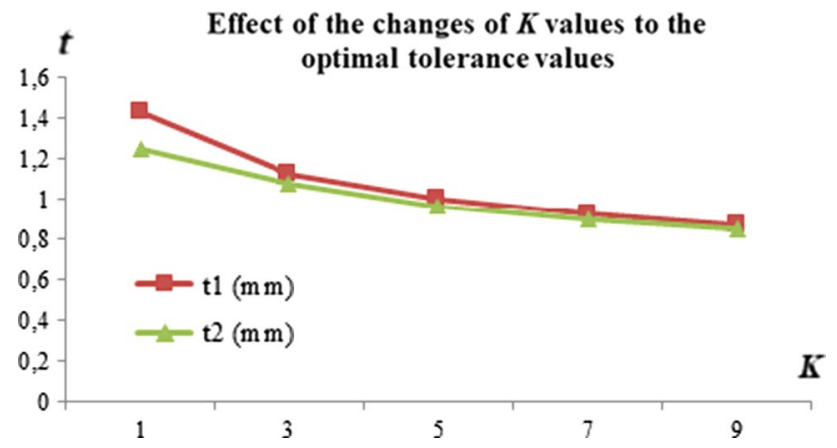

Fig. 5 Effect of the changes in $K$ values to the optimal tolerance values

\section{Effect of the changes of $K$ values to the optimal total cost per unit}

\section{total cost/unit}

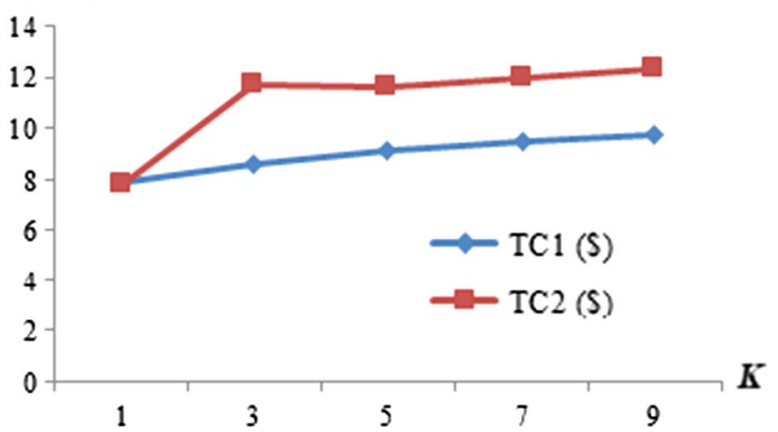

Fig. 6 Effect of the changes in $K$ values to the optimal total cost per unit

product decreases and it makes the manufacturer to tighten the tolerance value to meet the target quality.

On the other hand, if the value of $K$ increases, the total cost per unit will also increase as the cost for manufacturing the product will be higher to meet the target quality. Automatically, the quality investment will also increase to improve the quality. Figure 6 shows how sensitive the total cost per unit is to the changes in $K$.

Figures 7 and 8 describe the effect $\alpha$ to the optimal solution of the model. Parameter $\alpha$ is a coefficient whose value may be obtained using regression method. The value of $\alpha$ is influenced by several factors related to the provision of training, improvement in technology, as well as other matters related to the reduction in variance. The greater the value of $\alpha$, the greater the provision of training, improvement in technology, as well as other efforts related to the reduction in variance. Figure 7 shows the effect of $\alpha$ to the value of investment quality on rework Policy 1 . From the figure, we can see that the greater the value of $\alpha$, the greater the optimal investment.

\section{Effect of the changes of $\alpha$ values to the optimal quality investment on Policy 1}

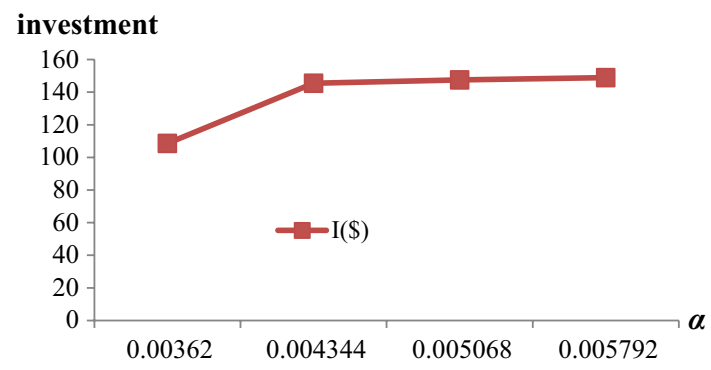

Fig. 7 Effect of the changes in $\alpha$ values to the optimal quality investment on Policy 1

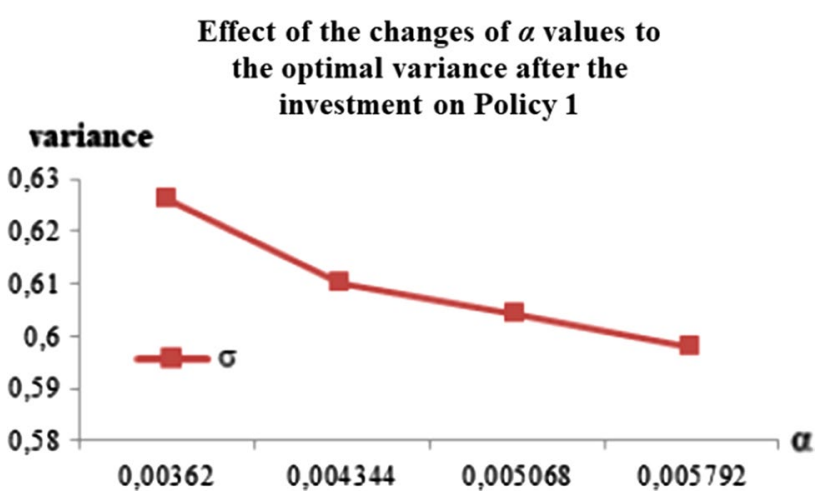

Fig. 8 Effect of the changes in $\alpha$ values to the optimal variance after the investment on Policy 1

Figure 8 shows the effect of $\alpha$ to the optimal variance after investment on the rework Policy 1 . The figure shows that the greater the value of $\alpha$, the optimal variance becomes smaller. This is because $\alpha$ is influenced by the amount of training, technological improvement, and other things related to the reduction in variance, which means the quality is also better so that the optimum variance is also getting smaller.

Figure 9 describes the effect of the changes in the appraisal cost to the quality cost after rebate. Appraisal cost is the cost incurred to identify poor-quality products before being sent to customers. Appraisal costs represent costs incurred by component checking activity at the supplier level, before the components are shipped to the next supplier or to the manufacturer. The higher the appraisal cost, the greater the quality cost of each supplier and manufacturer. This is because the cost of appraisal is the cost that arises from the activity of checking the components at the supplier side before the components are sent to the supplier at the next tier or to the manufacturer, so it will increase the quality cost that must be issued by the supplier and the manufacturer. 


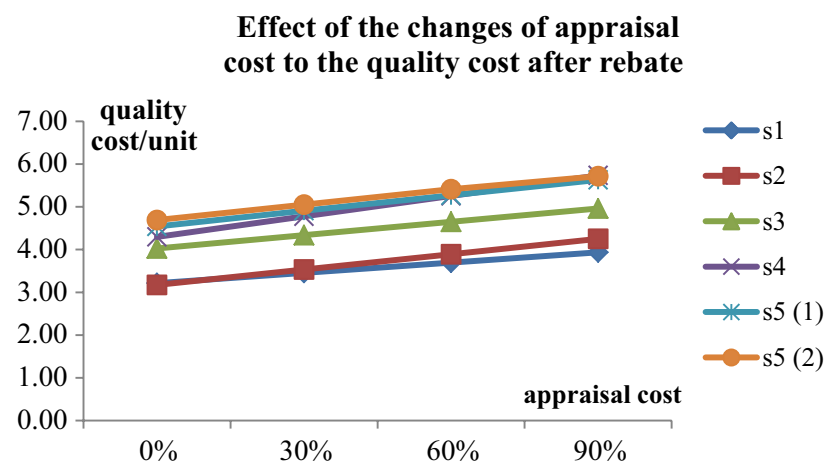

Fig. 9 Effect of the changes in appraisal cost to the quality cost after rebate

Figure 10 describes the effect of changing the value of internal failure cost to the quality level after rebate. Failure costs are incurred due to defective products. In the model, suppliers at the next tier not only bear the cost of failure due to a defect in the product in the supplier's process, but also share the cost of failure due to defective products processed on previous-tier suppliers. The higher the failure cost, the smaller the quality level of each supplier and manufacturer. This is due to the more defective products which lower the quality of the process from the supplier and the manufacturer.

Figure 11 describes the effect of change failure cost to the quality cost after rebate. The greater the failure cost, the greater the quality cost of each supplier and manufacturer. This is because the failure cost is the cost that arises because there are defective products, so the higher the cost it will add to the quality cost to be incurred by suppliers and manufacturer.

From the model presented in this paper, several managerial implications can be stated. First, the managers can make economic investment decisions economically to correct the defective product through cost optimization model and to

\section{Effect of the changes of internal failure cost to the quality level after rebate}

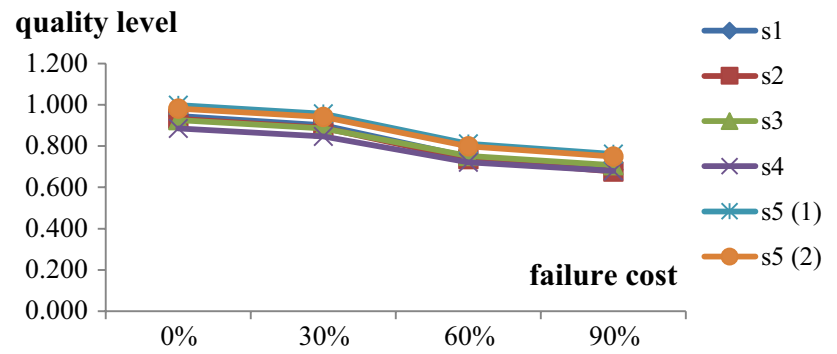

Fig. 10 Effect of the changes in internal failure cost to the quality level after rebate

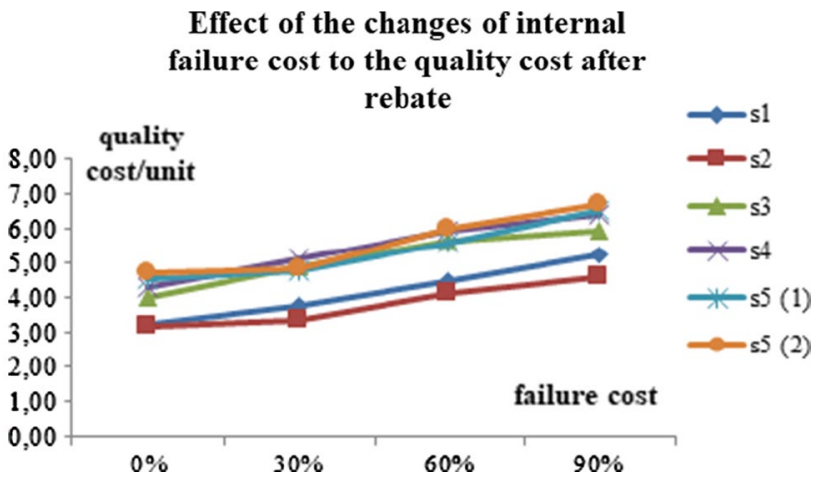

Fig. 11 Effect of the changes in internal failure cost to the quality cost after rebate

choose the best option toward the goal of least production cost. Second, they also can determine the optimal profit sharing or rebates that should be given by the manufacturer or second-tier suppliers to the first-tier suppliers capable of improving the quality. Hence, the quality of supplier process can be maintained and improved continuously.

\section{Conclusion}

In this paper, we presented two policies of quality improvement in a manufacturing process which performs inspection and rework considering profit sharing in the supply chain. In the first policy, the rework was done using the same manufacturing facility, while in the second policy additional process facility was added for the rework. For the first policy, we integrated two cost models comprising tolerance model and quality investment model. In addition to quality improvement in the form of rework policy selection and optimal investment value as mentioned previously, quality improvement in the supply chain environment is also necessary. The profit sharing system is used in the supply chain to increase the efforts of suppliers in quality improvement. This system is performed by providing a share of the manufacturer's profits to the supplier if the supplier can meet or exceed the quality target specified by the manufacturer in the form of incentives. With this system, the suppliers will try to improve their product quality while minimizing costs throughout the supply chain of quality in order to run more efficiently. By minimizing the sum of total costs, the optimal tolerances, quality investment, and the optimal profit sharing or rebates that should be given by the manufacturer or second-tier supplier to the first-tier suppliers capable of improving the quality can be obtained for both policies.

In the numerical example, it was shown that this model is applicable in the manufacturing process and showed how the model reacts and managerial implications to the changes in the parameters such as Taguchi loss constant $K, \alpha$, appraisal 
cost, and internal failure cost. It can be used as a guideline for managers in analyzing the choices of process improvement. For further research, the model can be extended by considering multistage processes, inspection, and corrections. Another consideration can be given by considering other distributions rather than normal distribution, such as uniform and exponential.

Open Access This article is distributed under the terms of the Creative Commons Attribution 4.0 International License (http://creativeco mmons.org/licenses/by/4.0/), which permits unrestricted use, distribution, and reproduction in any medium, provided you give appropriate credit to the original author(s) and the source, provide a link to the Creative Commons license, and indicate if changes were made.

\section{References}

Abdul-Kader W, Solaiman A, Ganjavi O (2008) An integrated production cost model with possibility to reduce rework/scrap cost, ASAC 2008. Halifax, Nova Scotia

Abdul-Kader W, Ganjavi O, Solaiman A (2010) An integrated model for optimisation of production and quality costs. Int J Prod Res 48(24):7357-7370

Chen JM, Tsou JC (2003) An optimal design for process quality improvement: modeling and application. Prod Plan Control 14(7):603-612

Chiu YP (2003) Determining the optimal lot size for the finite production model with random defective rate, the rework process, and backlogging. Eng Optim 35(4):427-437

Chiu SW (2007) Optimal replenishment policy for imperfect quality EMQ model with rework and backlogging. Appl Stoch Models Bus Ind 23(2):165-178

Chiu SW, Chiu YP (2003) An economic production quantity model with the rework process of repairable defective items. J Inf Optim Sci 24(3):569-582

Fathi Y (1990) Producer-consumer tolerances. J Qual Technol 22(2):138-145

Ganeshan R, Kulkarni S, Boone T (2001) Production economics and process quality: a Taguchi perspective. Int J Prod Econ 71:343-351

Hallgren M, Olhager J (2006) Differentiating manufacturing focus. Int J Prod Res 44:3863-3878

Hong JD, Hayya JC (1993) Process quality improvement and setup reduction. Oper Res 31(1):2693-2708

Irianto D (1996) Inspection and correction policies in setting economic product tolerance. Int J Prod Econ 46-47:587-589

Irianto D (2009) A model for process selection optimization for MTO manufacturer with imperfect repair. In: The 10th Asia pasific industrial engineering \& management systems (APIEMS) conference, pp 257-262

Irianto D, Rahmat D (2008) A model for optimizing process selection for MTO manufacturer with appraisal cost. In: The 9th Asia Pasific industrial engineering \& management systems (APIEMS) conference, pp 220-225

Jeang A (1997) An approach of tolerance design for quality improvement and cost reduction. Int J Prod Res 35(5):1193-1211
Jeang A (2001) Combined parameter and tolerance design optimization with quality and cost. Int J Prod Res 39(5):923-952

Jerusalem MA, Lin SW, Irianto D (2016) A comprehensive model for process selection by considering offline and online quality control. J Adv Mech Des Syst Manuf 10(4):2016

Kapur KC (1989) An approach for development of specifications for quality improvement. Qual Eng 1(1):63-77

Kusukawa E, Kudo K, Ohta H (2006) Rebate system for quality improvement under supply chain environment. Int Fed Autom Control Inf Control Probl Manuf 12:617-622

Lo Y, Tang K (1990) Economic design of multi-characteristics models for a three-class screening procedure. Int J Prod Res 28:2341-2351

Modak NM, Panda S, Sana SS (2015) Two-echelon supply chain coordination among manufacturer and duopolies retailers with recycling facility. Int J Adv Manuf Technol 87(5):1531-1546

Modak NM, Modak N, Panda S, Sana SS (2018a) Analyzing structure of two-echelon closed-loop supply chain for pricing, quality and recycling management. J Clean Prod 171:512-528

Modak NM, Ghosh DK, Panda S, Sana SS (2018b) Managing green house gas emission cost and pricing policies in a two echelon supply chain. CIRP J Manuf Sci Technol 20(2018):1-11

Mustajib MI, Irianto D (2010) An integrated model for process selection and quality improvement in multi-stage processes. J Adv Manuf Syst 9(1):31-48

Overvest B, Veldman J (2008) Managerial incentives for process innovation. Manag Decis Econ 29(7):539-545

Panda S, Modak NM, Basu M, Goyal SK (2015) Channel coordination and profit distribution in a social responsible three-layer supply chain. Int J Prod Econ 168:224-233

Porter M (1980) Competitive strategy. Free Press, New York

Rosyidi CN, Nugroho AW, Jauhari WA, Suhardi B, Hamada K (2016a) Quality improvement by variance reduction of component using learning investment allocation model. In: 2016 IEEE international conference on industrial engineering and engineering management (IEEM), pp 391-394

Rosyidi CN, Pamungkas IBP, Jauhari WA, Suhardi B, Hamada K (2016b) An investment allocation model for quality improvement to reduce component variances at manufacturer and supplier side to maximize the return on investment. In: 2016 IEEE international conference on industrial engineering and engineering management (IEEM), pp 1713-1716

Taguchi G (1989) Introduction to quality engineering. Unipub, White Plains, New York, pp 21-22

Taguchi G, Elsayed E, Hsiang T (1989) Quality engineering in production system. McGraw Hill Book Company, New York, pp 12-21

Veldman J, Gaalman G (2013) A model of strategic product quality and process improvement incentives. Int $\mathbf{J}$ Prod Econ 149(2014):202-210

Vokurka RI, Davis RA (1996) Quality improvement implementation: a case study in manufacturing scrap reduction. Prod Invent Manag J 37(3):63-68

Zhang G (1996) Simultaneous tolerancing for design and manufacturing. Int J Prod Res 34(12):3361-3382

Zhang HC, Hug HE (1992) Tolerancing techniques: the state-of-the-art. Int J Prod Res 30(9):2111-2135 